\title{
Sensory Evaluation of Aromatic Foods Packed in Developed Starch Based Films Using Fuzzy Logic
}

\author{
Tanima Chowdhury and Madhusweta Das ${ }^{a^{*}}$ \\ ${ }^{\text {a }}$ Department of Agricultural and Food Engineering Indian Institute of Technology, Kharagpur - 721302, India \\ ${ }^{*}$ Corresponding author \\ madhu@agfe.iitkgp.ernet.in \\ TEL: +91-3222-283108(O), $283113(\mathrm{R})$ \\ FAX: $+91-3222-282244 / 255303$
}

Received: 14 January 2014; Published online: 18 April 2015

\begin{abstract}
The last two decades have seen attempts to replace non biodegradable, synthetic food packaging films with alternatives made from biopolymers. The objective of the present work was to evaluate sensory quality of tea leaf and culinary tastemaker powder when sealed in pouches based on starch films. Films were developed from corn starch and a functional polysaccharide (FP) from amylose (AM), methylcellulose (MC), and hydroxypropylmethylcellulose (HPMC), using a casting technique. Pouches were stored inside a secondary package (plastic jar) under ambient condition for 90 days. Sensory attributes of the stored food samples were evaluated (tea in liquor form) and the scores analysed by fuzzy logic. Results were compared with similarly stored foods but using market available poly-pouches as packaging material.

For tea and tastemaker in general, the relative importance of the sensory attributes under consideration was assessed as: aroma (Highly important) $>$ taste (Highly important) $>$ colour (Highly important) $>$ strength (Important) for tea, and taste (Highly important) $>$ aroma (Highly important) $>$ colour (Important) > appearance (Important) for tastemaker. Among the three films that were developed, the highly important sensory attributes of aroma and taste were maintained as 'Very good' when the foods were packed in starch-HPMC/AM film. When the products were packed in market-available polypouches they exhibited similar attributes. With the exception of 'Very good' maintenance of the colour of tastemaker by the commercial pouch, irrespective of film and food, the colour and strength/appearance were retained in the 'Good'-'Satisfactory' range. The overall sensory score of tea was also maintained as 'Very good' in starch-HPMC film.
\end{abstract}

Keywords: Functional Polysaccharide; Packed Food; Self-Supporting Films; Sensory Qualities; Starch Based Films

\section{Introduction}

Aroma compounds are small organic molecules, for example alcohols, esters, aldehydes, ketones, alkenes, pyridines, etc., having high saturated vapour pressure and are generally hydrophobic (Hambleton, Debeaufort, Bonnotte, \& Voilley, 2009; Boonsong, Laohakunjit, Kerdchoechuen, \&
Tusvil, 2009). The permeability of these volatile compounds through polymer films is a function of their adsorption, solubility and diffusivity in the film guided by composition and structure of the film matrix (Boonsong et al., 2009). Loss of aroma compounds in foods, therefore, is high through apolar plastic packaging (van Willige, 2002). Currently, the protection of aroma com- 
pounds in packed on-shelf food in the retail market is accomplished with the use of expensive, non-recyclable and non-biodegradable multilayered synthetic packaging films.

Hydrophilic biopolymers possess better aroma retention capacity (Das \& Bal, 1999). In a model food system containing aqueous starch dispersion and commercial strawberry flavour, Vidrih, Zlatić, and Hribar (2009) reported that starch had significant influence on retention of aroma compounds. Studies on interactions between solutions of polysaccharides (modified corn and waxy corn starches) and model aroma compounds (limonene, isoamyl acetate, ethyl hexanoate and B-ionone) using exponential dilution technique showed the aroma retention ability of the polysaccharides (Langourieux \& Crouzet, 1995). Terta, Blekas, and Paraskevopoulou (2006) reported retention of limonene and trans-2-hexenal in polysaccharide solutions from thermodynamic and kinetic standpoints. According to Jouquand, Malhiac, and Grisel (2006), retention of aroma by pure polysaccharide is different from that of a mixture of polysaccharides.

In order to alleviate the disposal problem of synthetic plastics, the last two decades has seen the development of plastics from biopolymers. Several analytical studies have reported permeability of aroma compounds through films prepared from methylcellulose (Debeaufort \& Voilley, 1994, 1995; Debeaufort, Tesson, \& Voilley, 1995; Quezada Gallo, Debeaufort, \& Voilley, 1999), purified starches from potato (Yilmaz, Jongboom, Feil, van Dijk, \& Hennink, 2004) and cassava (Boonsong et al., 2009), hydroxypropylated maize starch (Sereno, Hill, Taylor, Mitchell, \& Davies, 2009), a mixture of iota carrageenan and sodium alginate (Fabra et al., 2008), and sodium caseinate (Fabra, Hambleton, Talens, Debeaufort, \& Chiralt, 2011). In all these analyses, commercially available pure aroma compounds were selected. However, aroma of food arises from a mixture of components, and the human is the best judge of olfactory sensations. Moreover, human perception is always fuzzy and the evaluators by nature prefer to express their opinion in linguistic form. Therefore, it is more realistic to use linguistic assessments instead of numerical values for sensory evaluation. Fuzzy logic is an important tool by which the sensory scores obtained in linguistic form, are analysed and con- clusions regarding acceptance, rejection, ranking and the strong and weak quality attributes of the food can be obtained (Chakraborty, Das, \& Das, 2013). Fuzzy logic has been applied to food testing by a number of researchers (Uprit \& Mishra, 2002; Jaya \& Das, 2003; Das, 2005; Routray \& Mishra, 2012; Sinija \& Mishra, 2011; Singh, Mishra, \& Mishra, 2012).

Physicochemical interactions between aroma compounds and methylcellulose in films induce plasticization (Quezada Gallo et al., 1999). Excessive plasticization will lead to more water vapour transmission as well as aroma loss, thus destroying overall quality of packaged food material. Therefore, the ability of a film to protect aroma and other sensory qualities of a food can be assessed effectively if the food is packed in the test film, stored in regulated environment and the qualities of the packed food are monitored. Jang, Shin, and Song (2011) compared the sensory scores of strawberry pouched in direct contact with a film (primary package) prepared from rapeseed protein and gelatin along with grape seed extract as an antimicrobial agent, and strawberry packed in polyethylene terephthalate (PET) boxes. Using a nine-point hedonic scale, the former showed better sensory scores than that of the latter. Apple wraps applied on fresh-cut apple slices were more effective than coatings to increase shelf life, reduce moisture loss and browning (McHugh \& Senesi, 2000). According to Du et al. (2012), paired sensory preference tests indicated no difference between baked chicken wrapped with tomato and apple films containing $0.5 \%$ plant antimicrobials, such as carvacrol and cinnamaldehyde, compared to chicken wrapped with tomato or apple films without antimicrobials added. Reports on the retention/loss of sensory attributes of foods packed in starch based films is absent.

Starch is a cheap and abundantly available biopolymer. However, films made from it have poor mechanical and barrier properties due to its amylopectin fraction. Starch films fortified with functional polysaccharides have shown improvements in these properties (Rindlav-Westling, Stading, \& Gatenholm, 2002; Paes, Yakimets, \& Mitchell, 2008; Tao, Cui, Ji, Ma, \& Wo, 2007). The present work was aimed at ranking sensory attributes of some selected aromatic foods packed in self-supporting films prepared from corn starch 
Sensory Quality Retention of Packed Foods |31

along with a functional polysaccharide (FP), amylose (AM), methylcellulose (MC) or hydroxypropylmethylcellulose (HPMC), using fuzzy logic.

\section{Materials and Methods}

\subsection{Materials}

White free flowing corn starch powder of commercial grade (ANGEL LK18, Angel Starch and Chemicals Pvt. Ltd., Tamil Nadu, India) was used as the basic raw material. Standard analysis of the starch indicated moisture, amylose, protein $(\mathrm{N} \times 6.25)$, fat, and ash $\left(550^{\circ} \mathrm{C}\right.$ for $\left.4 \mathrm{~h}\right)$ contents, respectively, as 13.46, 21.70, 0.35, 0.04, and $0.02 \%$ on wet basis. Potato AM (Sigma Chemical Company, USA), MC (methoxy content 28$32 \%$, Loba Chemie Pvt. Ltd., Mumbai, India) and HPMC (Hi Media Pvt. Ltd., India) were used as the $\mathrm{FP}(\mathrm{s})$. Since the presence of gelatin in film formulation may lead to formation of triple helix structure of native collagen that act as 'initiators' for the development of a three-dimensional network (Arvanitoyannis, Nakayama, \& Aiba, 1998), a fixed amount of gelatin (Loba Chemie Pvt. Ltd., Mumbai, India) was added in the blends containing MC. Glycerol (87\%, AR, Merck Specialities Pvt. Ltd., Mumbai, India) and distilled water were used as plasticizers. Sodium propionate (Analar grade, Loba Chemie Pvt. Ltd., Mumbai, India) was used as antimicrobial agent.

Commercially available tea leaf and culinary tastemaker powder, both having good flavour, were used as aromatic foods.

\subsection{Methods}

\section{Preparation of Blend and Casting of Film}

Pre-optimized compositions (corresponding to maximum tensile strength and minimum water vapour permeability of films) were used for preparation of films (Chowdhury, 2013). All the biopolymers and plasticizers added in blends were expressed as percent, i.e., \%, weight $(\mathrm{w}) /$ weight $(\mathrm{w})$ of blend [(calculated as weight of ingredient/weight of blend) $\times 100]$. Blends were classified in three groups, viz., Starch-AM, Starch-MC, and Starch-
HPMC, all containing $6 \mathrm{~g}$ total polymer in 80 $\mathrm{ml}$ plasticizer $(78 \mathrm{ml}$ water i.e. $90.21 \%$, and 2 $\mathrm{ml}$ glycerol i.e. $2.85 \%$; water:glycerol $=31.6: 1)$. Polymer composition corresponded to: $0.65 \%$ $\mathrm{AM}+\quad 6.29 \% \quad$ starch $\quad$ (starch:AM=9.6:1); $0.10 \% \quad \mathrm{MC}+1.16 \% \quad$ gelatin $+5.68 \%$ starch (starch:MC=56.8:1); and 0.22\% HPMC $+6.72 \%$ starch (starch:HPMC=30.5:1). Sodium propionate was incorporated in all the three blends in a weight ratio of 0.185:100.

Functional polysaccharide(s) was initially dissolved in $30 \mathrm{ml}$ of water in a $250 \mathrm{ml}$ conical flask; solubilisation of HPMC and MC, however, required overnight soaking and followed by heating in a boiling water bath for about $10 \mathrm{~min}$ to obtain clear solution. For HPMC and AM containing blends, the required amount of cornstarch was dispersed in another $30 \mathrm{ml}$ portion of water and transferred to the FP solution at room temperature. For the MC blend, gelatin was dissolved separately in $30 \mathrm{ml}$ water and to this starch was added for dispersion, and then the mixture was transferred to the MC solution. Transfer operations were done quantitatively by washing with aliquots of water. Glycerol and remaining water was added to each system, and mixed well manually with spatula.

The prepared blend in a $250 \mathrm{ml}$ conical flask was gelatinized by heating in a boiling water bath for 10 min with continuous stirring using a spatula. As much as possible of the hot gelatinized mass was quickly poured in the channel of a Thin Layer Chromatography (TLC) applicator and spread onto a polypropylene plate (area: $33 \mathrm{~cm} \times 33$ $\mathrm{cm}$, thickness: $0.5 \mathrm{~cm}$ ), maintaining a thickness of $2 \mathrm{~mm}$. The film was dried in a temperaturecontrolled incubator at $40 \pm 1{ }^{\circ} \mathrm{C}$ for $24 \mathrm{~h}$ and peeled off from the plate. The dried films were transparent, self-supporting, easy to handle, and flexible. The thickness of films ranged within 65$105 \mu \mathrm{m}$. Similar values of thickness have also been reported by different workers working on yam starch, sago starch, HPMC, and chitosan, either used as sole polymer or as mixture (Mali, Grossmann, Garcia, Martino, \& Zaritzky, 2004; Maizura, Fazilah, Norziah, \& Karim, 2007; Sebti, Chollet, Degraeve, Noel, \& Peyrol, 2007). Films were stored in ambient conditions as described elsewhere (Das, 2008; Chowdhury \& Das, 2010). For each composition, 10-12 films were cast. 


\section{Preparation of Pouches}

Two cut pieces of equal size of films, placed one on another, were heat sealed along three sides, keeping one side open for filling. Tea leaf and tastemaker powder, $3-4 \mathrm{~g}$ of each, were filled in respective pouches $\left(15-22 \mathrm{~cm}^{2}\right.$ area) and the open side sealed. For comparison with commercially available packaging material, tea was also packed in market available flexible aluminium foil $(\mathrm{Al})$ pouch and the open side subsequently sealed, whereas the market available commercial tastemaker pouch (opaque) was used as such. The pouches were stored inside secondary packaging (PET plastic jars: $11 \mathrm{~cm}$ length $\mathrm{x} 10.2 \mathrm{~cm}$ width x $22 \mathrm{~cm}$ height; accommodating $25-30$ pouches per jar) for 90 days at room temperature varying between $25 \pm 2{ }^{\circ} \mathrm{C}$ and $33 \pm 2{ }^{\circ} \mathrm{C}$. To avoid cross contamination of aroma, a jar contained only similar pouches. A cotton sachet containing anhydrous calcium chloride crystals was placed at the bottom of each jar to keep it dry. A piece of tissue paper covering the whole bottom surface was layered over this sachet to avoid direct contact of the food pouches with the latter. Fig. 1 shows some of the pouches and storage jars. After 90 days of storing, the pouches were cut and the tea and tastemaker powder were evaluated for sensory quality by subjective method using fuzzy logic.

\section{Preparation of Sample for Sensory Evaluation}

Tea liquor was prepared for tasting as described by Lee and Chambers (2007). For this, water (deionised carbon filtered water obtained through reverse osmosis from Aquaguard Total Protec ${ }^{+} \mathrm{RO}$ water purifier, Eureka Forbes Pvt. Ltd., Mumbai, India) heated at $70{ }^{\circ} \mathrm{C}$ was poured into a glass container containing the tea leaves in a ratio of $2.55 \mathrm{~g}$ tea leaves: $150 \mathrm{ml}$ water. The container was covered and allowed to brew for 2 min during which time the contents were swirled 10 times. The liquor/sample attained a temperature of 50 ${ }^{\circ} \mathrm{C}$, and was strained and served in plastic cups to the judges for evaluating the various attributes. Tastemaker, as such, was also served in plastic cup.

\section{Sensory Evaluation}

Following the method of Longares, Monahan, O'Riordan, and O'Sullivan (2004) and Chinma, Ariahu, and Abu (2012), twenty five judges (12 men and 13 women, age range 24-55 years) from non-smokers and non-beetle leaf chewers belonging to students and staff of the Agricultural and Food Engineering Department of Indian Institute of Technology, Kharagpur, were selected. The panelists were semi-trained and had good health, average sensitivity, interest in sensory evaluation, ability to concentrate and learn, and familiarity with tea and tastemaker (Ranganna, 1986). Quality attributes selected for sensory evaluation of tea samples were aroma, colour, taste and strength (thickness of liquor) (UPASI, 2014), and those for tastemaker were aroma, colour, taste and appearance. Judges were asked to rate the products for these sensory attributes. They were also familiarized with the definitions of quality attributes, score-card, and the method of scoring, and asked not to make hasty judgements. Advice was first to sniff the food and score for aroma, followed by 'tasting' for other qualities. They were advised to rinse their mouth with water between tasting the consecutive samples (Ranganna, 1986). For evaluating the quality attributes of tea and tastemaker, the sample packed in pouches made of film containing HPMC, AM and MC were labelled as Sample 467, Sample 785, and Sample 598, respectively. Both, aluminium pouches for tea and market available tastemaker pouches for tastemaker samples were labelled as Sample 770. The order of presentation of samples to the judges was randomised (Longares et al., 2004; Chinma et al., 2012).

In the score card, five point sensory scale factors viz., Not satisfactory (NS), Fair (F), Medium (M), Good $(\mathrm{G})$, and Excellent (EX) were assigned to each of the quality attributes irrespective of the products (tea or tastemaker). Each of the judges was given an individual card and asked to give tick $(\sqrt{ })$ mark to appropriate scale factor for all the quality attributes of samples after evaluation. In the same score card, judges were also asked to evaluate the relative importance (weighting) of the four quality attributes usually scored for tea and commercial tastemaker in general, on the basis of another five point sensory scale viz., Not at all important (NI), Somewhat important (SI), Im- 
portant (I), Highly important (HI), and Extremely important (EI).

\section{Fuzzy Logic Analysis}

The results were analyzed by fuzzy logic to find out the overall ranking for tea and tastemaker, most and least important quality attributes of these food materials in general, and strong and weak quality attributes of each of the four samples of tea and tastemaker tested. Number of judges in similar category was counted.

The major steps involved in the fuzzy modelling of sensory evaluation were: (i) calculation of triplets (a set of three numbers) for a) sensory score of particular quality attributes of samples i.e., tea and tastemaker, b) sensory score of quality attributes in general, c) relative weighting of quality attributes in general, and d) overall sensory scores of samples, (ii) calculation of membership functions of sensory scores on a standard fuzzy scale, (iii) estimation of similarity values and the ranking of both tea and tastemaker samples, (iv) quality attribute ranking of both the items in general, and (v) quality attribute ranking of individual tea and tastemaker samples (Uprit \& Mishra, 2002; Jaya \& Das, 2003; Das, 2005; Routray \& Mishra, 2012; Sinija \& Mishra, 2011; Singh et al., 2012). Details of calculations are discussed below by taking the tea sample as an example. Tastemaker was analysed exactly in the same way.

\section{Calculation of Triplets}

\section{i Triplets for Sensory Scores of Quality Attributes of Sample}

Using the number of judges in similar category and the standard form of triplets associated with five point sensory scale (Table 1) as derived from triangular membership distribution pattern (Fig. 2), triplets for the sensory scores of a quality attribute of a particular sample was evaluated. In Fig. 2, triangle 'a b c' represents membership distribution function for Not satisfactory/Not at all important category, whereas triangle 'a $c_{1}$ d' represents the corresponding function for Fair/Somewhat important category, etc. In triplets in Table 1, the first number denotes the coordinate of the abscissa where the value of the membership function is 1 , and the second and third numbers with zero membership function indicate the distance to the left and right, respectively, of the first number. For example, for the aroma attribute of tea Sample 598 (S598), out of a total of 25 judges, say none had rated the sample as 'Not satisfactory', 2 judges scored as 'Fair', 3 of them scored as 'Medium', 14 judges gave 'Good' and the remaining 6 judges as 'Excellent'. Therefore, triplets of the sensory score for aroma of that sample was calculated as,

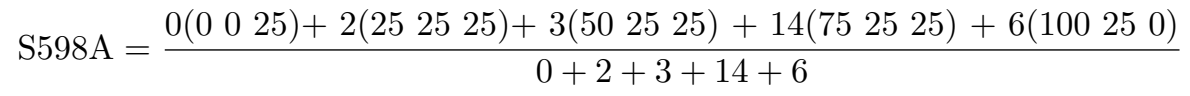

Similar calculation was followed for all the quality attributes of tea sample as presented below.

$$
\begin{aligned}
\mathrm{S} 598 \mathrm{~A} & =\left(\begin{array}{lll}
74 & 25 & 19
\end{array}\right) \\
\mathrm{S} 598 \mathrm{C} & =\left(\begin{array}{lll}
52 & 23 & 25
\end{array}\right) \\
\mathrm{S} 598 \mathrm{~T} & =\left(\begin{array}{lll}
54 & 25 & 23
\end{array}\right) \\
\mathrm{S} 598 \mathrm{~S} & =\left(\begin{array}{lll}
51 & 24 & 25
\end{array}\right)
\end{aligned}
$$

ii Triplets for Judges' Evaluation of the Importance of Quality Attributes of Tea in General
Triplet representation for the judges' evaluation of the importance of quality attributes in general (Not at all important (NI), Somewhat important (SI), etc.) was obtained from Eq. (1) i.e., from sum of the sensory scores, values of triplets associated with five point sensory scale (Table 1 ), and total number of judges. For the aroma attribute of tea in general, value of its triplet QA was calculated as, 


$$
\mathrm{QA}=\frac{0(0025)+1(252525)+3(502525)+15(752525)+6(100250)}{0+1+3+15+6}=\left(\begin{array}{ll}
76 & 2519
\end{array}\right)
$$

where $0,1,3,15$, and 6 are the number of judges rated as NI, SI, I, HI, and EI, respectively. Similar calculations were done for the other quality attributes for tea samples viz., colour (QC), taste (QT) and strength (QS) as shown in Eq. (2).

$$
\begin{aligned}
\mathrm{QA} & =\left(\begin{array}{lll}
76 & 25 & 19
\end{array}\right) \\
\mathrm{QC} & =\left(\begin{array}{lll}
76 & 25 & 14
\end{array}\right) \\
\mathrm{QT} & =\left(\begin{array}{lll}
87 & 25 & 9
\end{array}\right) \\
\mathrm{QS} & =\left(\begin{array}{lll}
68 & 24 & 16
\end{array}\right)
\end{aligned}
$$

iii Triplets for Relative Weighting of Quality Attributes in General

To find out relative weighting of quality attributes in general, the sum $\left(\mathrm{Q}_{\text {Sum }}\right)$ of first digit of triplets (Eq. 2) of QA, QC, QT and QS was obtained i.e., for tea in general

$$
\mathrm{Q}_{\text {Sum }}=76+76+87+68=307
$$

Triplet for relative weighting of aroma was obtained as,

$$
\begin{aligned}
\mathrm{QA}_{r e l} & =\mathrm{QA} / \mathrm{Q}_{\text {Sum }} \\
& =(76 / 307,25 / 307,19 / 307) \\
& =\left(\begin{array}{lll}
0.248 & 0.081 & 0.062
\end{array}\right)
\end{aligned}
$$

Similarly, relative weighting of other quality attributes for tea samples, viz., colour $\left(\mathrm{QC}_{r e l}\right)$, taste $\left(\mathrm{QT}_{r e l}\right)$ and strength $\left(\mathrm{QS}_{r e l}\right)$ were calculated. The comprehensive result is given in Eq. (3)

$$
\begin{aligned}
\mathrm{QA}_{r e l} & =\left(\begin{array}{lll}
0.248 & 0.081 & 0.062
\end{array}\right) \\
\mathrm{QC}_{\text {rel }} & =\left(\begin{array}{lll}
0.248 & 0.081 & 0.046
\end{array}\right) \\
\mathrm{QT}_{\text {rel }} & =\left(\begin{array}{lll}
0.283 & 0.081 & 0.029
\end{array}\right) \\
\mathrm{QS}_{\text {rel }} & =\left(\begin{array}{lll}
0.222 & 0.078 & 0.052
\end{array}\right)
\end{aligned}
$$

\section{iv Triplets for Overall Sensory Score of Samples}

To find out the triplets for overall sensory scores of tea samples, triplet for sensory score for each quality attribute was multiplied with the triplet for relative weighting of that particular attribute in general, and the sum of resultant triplet values for all attributes was taken. The rule of multiplication of triplet (a b c) with triplet ( $\mathrm{d}$ e f) as given by the following Eq. (4) was applied here,

$$
(a b c) \times(d \text { e f })=(a \times d a \times e+d \times b a \times f+d \times c)
$$

Thus, triplets associated with overall sensory score for tea sample 598 was calculated using the triplet multiplication rule (Eq. 4)

$$
\mathrm{SO} 598=\mathrm{S} 598 \mathrm{~A} \times \mathrm{QA}_{r e l}+\mathrm{S} 598 \mathrm{C} \times \mathrm{QC}_{r e l}+\mathrm{S} 598 \mathrm{~T} \times \mathrm{QT}_{r e l}+\mathrm{S} 598 \mathrm{~S} \times \mathrm{QS}_{r e l}
$$


where S598A, S598C, S598T, and S598S represent the triplets corresponding to the aroma, colour, taste, and strength of Sample 598, and $\mathrm{QA}_{r e l}, \mathrm{QC}_{r e l}, \mathrm{QT}_{r e l}$, and $\mathrm{QS}_{r e l}$ denote the triplets of relative weighting corresponding to these quality attributes of tea in general.

\section{Membership Function of Overall Sensory Scores on Standard Fuzzy Scale}

Standard fuzzy scale is referred to the 6-point sensory scale as shown in Fig. 3 where symbols F1, F2, F3, F4, F5, and F6, represent sensory scales: Not satisfactory/Not at all necessary, Fair/Somewhat necessary, Satisfactory/Necessary, Good/Important, Very Good/Highly important, and Excellent/Extremely important, respectively. Maximum value of membership function for each of the sensory scale is 1 in the triangular distribution pattern. Values of membership function of F1 through F6 are defined by a set of 10 numbers, as shown in Eq. (6), where each digit within bracket sequentially represents maximum value of fuzzy membership function between 0 and 10, 10 and 20,20 and $30, \ldots \ldots \ldots, 80$ and 90,90 and 100 .

$$
\begin{aligned}
& F 1=(1,0.5,0,0,0,0,0,0,0,0) \\
& F 2=(0.5,1,1,0.5,0,0,0,0,0,0) \\
& F 3=(0,0,0.5,1,1,0.5,0,0,0,0) \\
& F 4=(0,0,0,0,0.5,1,1,0.5,0,0) \\
& F 5=(0,0,0,0,0,0,0.5,1,1,0.5) \\
& F 6=(0,0,0,0,0,0,0,0,0.5,1)
\end{aligned}
$$

Fig. 4 shows the graphical representation of membership function of a triplet ( $\mathrm{a}$ b c ). In the figure, value of membership function is 1 when the value of abscissa is a, and its value is zero when the abscissa is less than $(a-b)$ or greater than $(a+c)$.

For a given value of $\mathrm{x}$ on the abscissa, value of membership function $\mathrm{B}_{x}$ can be expressed as Eq. (7)

$$
\begin{aligned}
\mathrm{B}_{x} & =\frac{x-(a-b)}{b} \text { for }(\mathrm{a}-\mathrm{b})<\mathrm{x}<\mathrm{a} \\
& =\frac{(a+c)-x}{c} \text { for } \mathrm{a}<\mathrm{x}<\mathrm{a}+\mathrm{c} \\
& =0 \text { for other values of } \mathrm{x}
\end{aligned}
$$

Corresponding to the triplets of overall sensory scores for each of the four samples for tea, value of membership function $\mathrm{B}_{x}$ at $\mathrm{x}=0,10,20,30,40$, $50,60,70,80,90$, and 100 was calculated by using Eq. (7). On standard fuzzy scale, this gives a set of 10 numbers as:

'maximum values of $\mathrm{B}_{x}$ at $0<\mathrm{x}<10,10<\mathrm{x}<$ $20,20<\mathrm{x}<30, \ldots \ldots \ldots ., 80<\mathrm{x}<90,90<\mathrm{x}$ $<100$ '

\section{Similarity Values and Ranking of the Tea Samples}

After getting the B values for each sample on standard fuzzy scale as a set of ten values, the similarity value for each sample was obtained by Eq. (8) (Chen, 1988):

$$
\mathrm{S}_{m}(\mathrm{~F}, \mathrm{~B})=\frac{\mathrm{F} \times \mathrm{B}^{\prime}}{\text { Maximum of }\left(\mathrm{F}^{\mathrm{x}} \mathrm{F}^{\prime} \text { and } \mathrm{B} \times \mathrm{B}^{\prime}\right)}
$$

where $S_{m}$ is the similarity value for the sample (e.g., tea Sample 598), F x B' is the product of the matrix $\mathrm{F}$ (Eq. 6) by the transpose of matrix B, F x $\mathrm{F}^{\prime}$ is the product of matrix $\mathrm{F}$ by its transpose, and B $\times \mathrm{B}^{\prime}$ is the product of matrix B by its transpose. For example, for Sample 598 of tea whose membership function on standard fuzzy scale is B598, under F1 category, F1 x B598', F1 x F1' and B598x B598' were calculated using matrix multiplication. The maximum value of F1x F1' and B598 x B598' was taken in the denominator and the value of $\mathrm{F} 1 \times$ B598' was taken in the numerator of Eq. (8). Similarity value was evaluated for each of $\mathrm{F} 1, \mathrm{~F} 2$, F3, F4, F5 and F6 of standard fuzzy scale (Fig. 3) and the highest similarity value was noted. Taking overall sensory score as an example, if the similarity value of a sample of tea was highest under F4 i.e., 'Good' category, the overall quality of that tea sample was regarded as 'Good'.

\section{Similarity Values for Quality Attribute Ranking of Tea in General}

The ranking of quality attributes for tea in general, was expressed by adopting the same procedure as mentioned above. Using the triplets for sensory scores of each of the four quality attributes in general (Eq. 2), the corresponding membership functions on standard fuzzy scale were calculated and the similarity values evaluated. By comparing the similarity values for each of the four quality criteria (aroma, colour, taste, strength), the order 


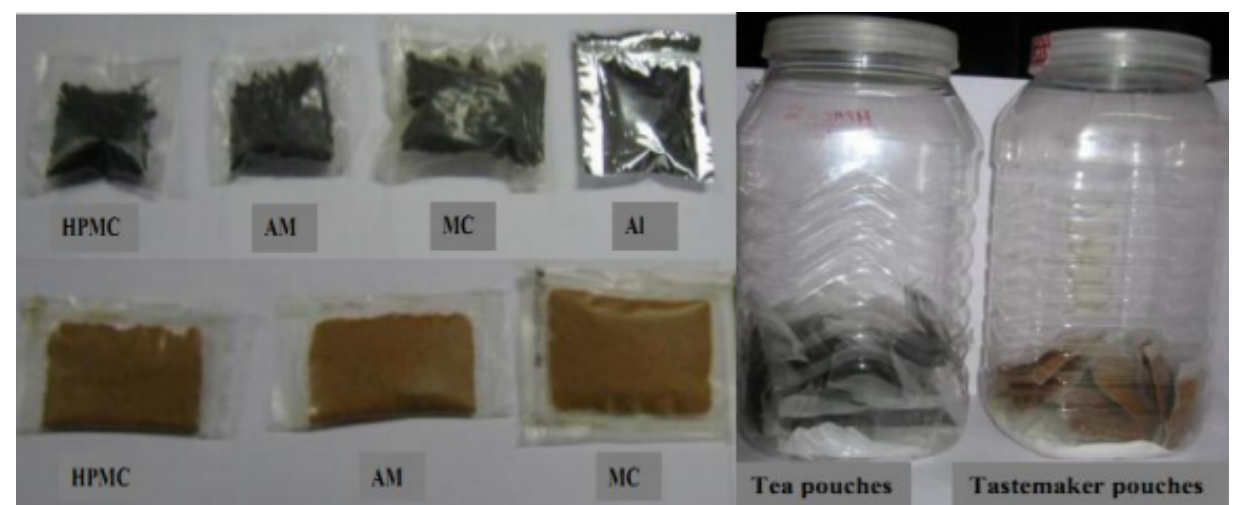

Figure 1: Pouches and Storing Jars

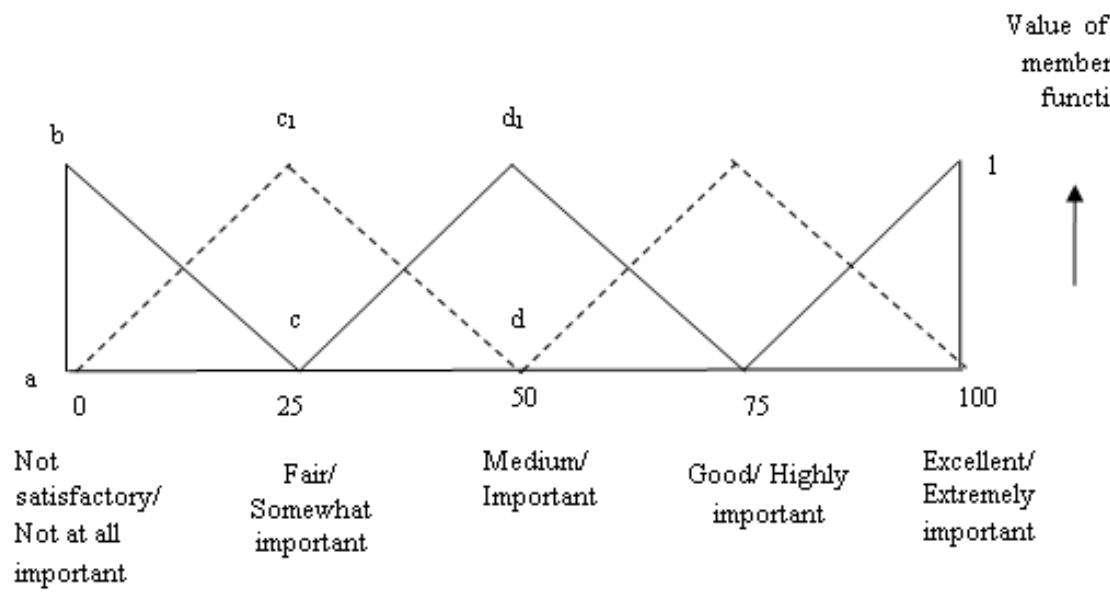

Figure 2: Representation of Triangular Membership Function Distribution Pattern of 5 Point Sensory Scale

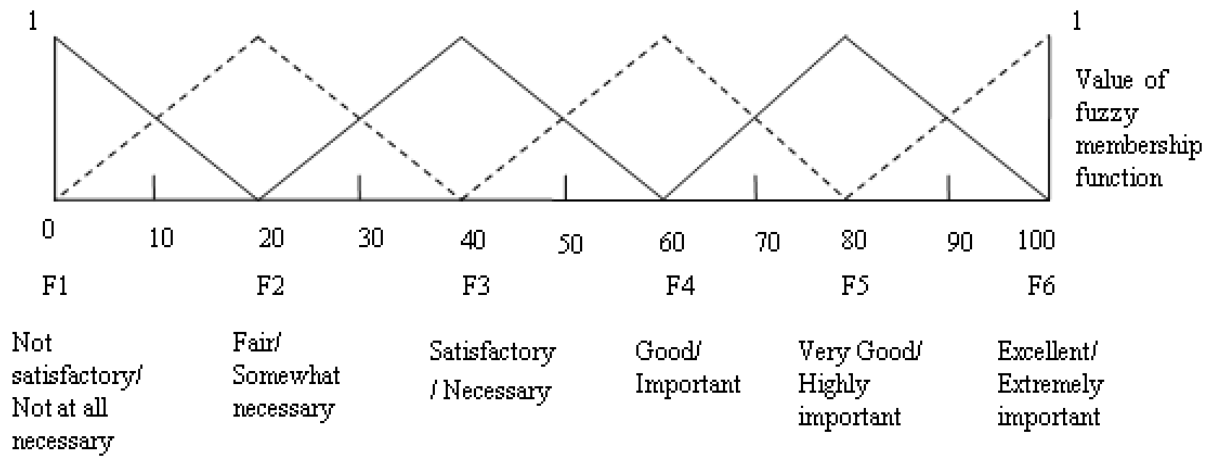

Figure 3: Standard fuzzy scale 


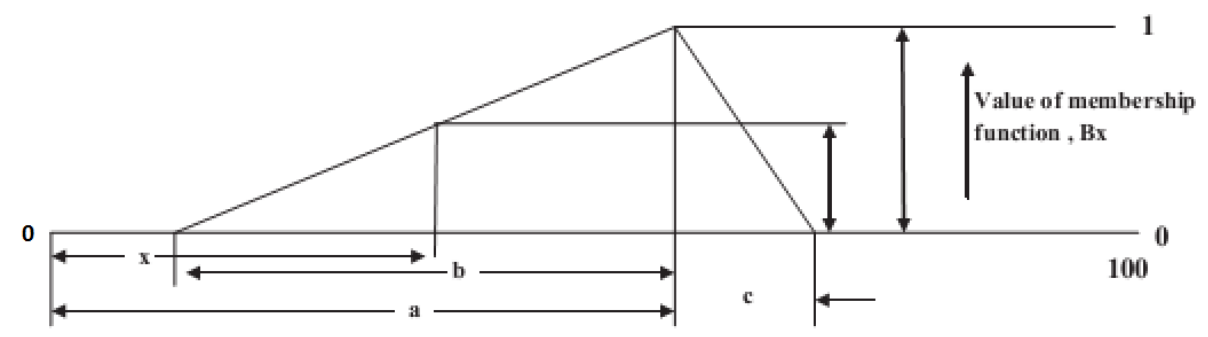

Figure 4: Graphical representation of overall sensory score as triplet (a b c) and its membership values

of ranking was framed. The category (viz., Not at all necessary, Somewhat necessary, Necessary, etc.) corresponding to the highest similarity value was regarded as the best quality criteria for tea in general.

\section{Similarity Values for Quality Attributes Ranking of Individual Tea Sample}

For finding the ranks of the four qualities attributes of each tea sample tested (Samples 467, 785, 598 and 770), similar procedure was adopted. For this ranking, triplets of sensory scores of four quality attributes of individual sample (Eq. 1) and triplets for relative importance of each of the quality attributes in general (Eq. 3) were used to find out the overall sensory scores for aroma, colour, taste and strength, respective to each sample. These triplets of overall sensory scores were converted to respective membership function. Similarity values of the four quality attributes of individual sample were then calculated, and the highest similarity value was regarded as the best quality criteria, whereas the lowest value denoted the weakest quality. The order of ranking of the quality attributes of individual sample was then determined based on the order of the similarity values.

An existing MATLAB 7.1 program (The Mathworks Inc., Natick, MA) was used for determining the sensory scores by following above mentioned steps.

\section{Results and Discussion}

\subsection{Triplets for Sensory Quality of Tea and Tastemaker Samples}

Tables 2 and 3 show the number of judges opting for the particular sensory preference category for tea and tastemaker, respectively, packed in different pouches viz., Samples 467, 785, 598 and 770 . The tables also contain the triplets associated with the sensory scores which were calculated as shown in Eq. (1).

\subsection{Triplets of Sensory Scores for Quality Attributes of Tea and Tastemaker Samples in General}

The judges' evaluations of the importance of quality attributes of tea and tastemaker in general, are shown in Table 4. Triplets for these sensory scores of quality attributes, in general, viz., aroma, colour, taste and strength for tea samples and aroma, colour, taste and appearance for tastemaker samples are included in this table. Table 4 also includes the relative weighting of these quality attributes. 


\subsection{Triplets for Overall Sensory Score of Tea and Tastemaker Samples and Their Membership Functions on Standard Fuzzy Scale}

Triplets for overall sensory scores of Sample 467 (SO467), Sample 785 (SO785), Sample 598 (SO598), and Sample 770 (SO770) for tea and tastemaker, as calculated by Eq. (5), are given below:

Overall sensory scores for tea

$$
\begin{aligned}
& \mathrm{SO} 467=74.478849 .087933 .0065 \\
& \mathrm{SO} 785=66.544045 .459333 .4007 \\
& \mathrm{SO} 598=57.791542 .928334 .1401 \\
& \mathrm{SO} 770=64.544045 .009833 .2345
\end{aligned}
$$

Overall sensory scores for tastemaker

$$
\begin{aligned}
& \text { SO467 }=69.974149 .507435 .1556 \\
& \text { SO785 }=66.933348 .566735 .4926 \\
& \text { SO598 }=62.903745 .977835 .8222 \\
& \text { SO770 }=81.888954 .525935 .9519
\end{aligned}
$$

Values of membership function for overall sensory scores of the tea and tastemaker samples on standard fuzzy scale (vide Eq. 7) are shown in Table 5 .

\subsection{Similarity Values and Ranking of Tea and Tastemaker Samples Based on Overall Quality}

Similarity values (according to Eq. 8) and the consequent ranking for tea and tastemaker samples packed in different packaging materials are presented in Table 6. For tea, Sample 467 had the highest similarity value $(0.7000)$ in the category 'Very good'. However, for Sample 785, 598 and 770 , the highest similarity value was obtained under the category 'Good' with the values of 0.7288 , 0.7479 and 0.7445 , respectively. Among the similarity values of Sample 785, 598 and 770, all indicated 'Good' category, Sample 598 showed the maximum value followed by Sample 770 and Sample 785. Therefore, ranking of all the samples of tea was Sample 467 (HPMC pouch) (Very good) > Sample 598 (MC pouch) (Good) > Sample 770 (Al pouch) (Good) > Sample 785 (AM pouch) (Good). Thus, it indicated that HPMC film pouch maintained the overall quality of tea in the best way, even better than tea packed by $\mathrm{Al}$ pouch.

In case of tastemaker samples (Table 6), Sample 770 gave the highest similarity value (0.7356) under the category 'Very good'. For Samples 598 (0.7275), 785 (0.6997) and 467 (0.6690), the similarity values were rated as 'Good'. Thus, ranking of the tastemaker samples was Sample 770 (market available pouch) (Very good) > Sample 598 (MC) $($ Good) $>$ Sample 785 (AM) (Good) > Sample 467 (HPMC) (Good). Thus, among the starch films containing different functional polysaccharide(s), $\mathrm{MC}$ containing film was more effective than those of $\mathrm{AM}$ and $\mathrm{HPMC}$ in maintaining overall quality of tastemaker.

\subsection{Quality Attributes Ranking of Tea and Tastemaker Samples in General}

Table 7 shows the similarity values and subsequent ranking for all the quality attributes of tea and tastemaker in general. The comparison of the values for tea in general (Table 7) showed that, the similarity value for aroma (0.9204) was the highest followed by taste $(0.8853)$ and colour (0.8377), and all these three attributes for tea were considered to be 'Highly important'. Similarity value for strength of tea was the lowest (0.8917) among all, and was rated to be 'Important'. Hence, the order of preference of quality attributes for tea in general, was aroma (Highly important) $>$ taste (Highly important) $>$ colour (Highly important) $>$ strength (Important). Liang et al. (2008) also reported that aroma, taste and colour are the major quality attributes for tea, and strength was the least important quality attribute as evaluated by Sinija and Mishra (2011). Similarly, both taste (0.9423) and aroma (0.8907) of tastemaker powder were perceived as 'Highly important', whereas colour (0.9700) and appearance (0.8741) were rated as 'Important'. Therefore, the order of preference for tastemaker in general, was 
taste (Highly important) $>$ aroma (Highly important) $>$ colour (Important) $>$ appearance (Important). Therefore, taste of the tastemaker sample was considered as the strongest quality attribute and appearance as the weakest.

\subsection{Quality Attribute Ranking of Individual Tea and Tastemaker Samples}

Similarity value of individual quality attribute of different tea and tastemaker samples are given in Tables 8 and 9, respectively.

Based on the similarity values as in Table 8 for tea samples, the order of ranking of the quality attributes of Sample 467, 785, 598 and 770 were as follows,

Sample 467 (starch-HPMC): aroma (Very good) $>$ taste (Very good) $>$ colour (Good) $>$ strength (Good)

Sample 785 (starch-AM): aroma (Very good) $>$ taste (Very good) > colour (Good) $>$ strength (Satisfactory)

Sample 598 (starch-MC): aroma (Very good) $>$ taste $($ Good) $>$ colour (Good) > strength (Satisfactory)

Sample $770(\mathrm{Al})$ : aroma (Very good) $>$ taste (Very good) > colour (Good) > strength (Satisfactory)

From Table 9, depending on the similarity values of tastemaker samples packed in different pouches, the order of ranking of the quality attributes were as follows,

Sample 467(starch-HPMC): taste (Very good) $>$ aroma (Very good) $>$ colour (Good) $>$ appearance (Satisfactory)

Sample 785(starch-AM): taste (Very good) $>\operatorname{aroma}($ Very good) $>$ colour (Good) $>$ appearance (Satisfactory)

Sample 598(starch-MC): taste (Very good) $>$ aroma $($ Good) $>$ colour $($ Good) $>$ appearance (Satisfactory)

Sample 770(market available): taste (Very good) $>$ aroma (Very good) $>$ colour (Very good) $>$ appearance (Good)

In addition to detrimental effects of water vapour, oxygen and volatiles permeating through film, a packaged food item, even a solid one, may lose its quality by absorbing undesirable flavours from the packaging material (Voilley, Debeaufort, \& Quezada-Gallo, 2002). In the present study, the developed films did not indicate such a problem. Samples 467 and 785 maintained the aroma and taste of tea as 'Very good', while colour and strength in 'Good'-'Satisfactory' range. In-vogue opaque $\mathrm{Al}$ pouch also maintained these qualities in similar manner. Sample 598 could preserve taste in the 'Good' category only, though for the other qualities retention was comparable. It is worth mentioning that assessors preferred aroma, taste and colour as the 'Highly important' criteria of tea (Table 7). For tastemaker powder in general, taste and aroma were the 'Highly important' requirements, whereas colour and appearance were considered 'Important'. Taste and aroma were maintained 'very good' with Samples 467 and 785, similar to that by commercial pouch. With the StarchMC pouch (Sample 598), however, there was deterioration of aroma to bring down to 'Good'. Regarding colour and appearance, commercial pouch exhibited best retention amongst all.

Diffusion of volatile compounds through starch film is augmented by moisture permeation vis-a-vis swelling (Habeych, van der Goot, \& Boom, 2007; Yilmaz et al., 2004; Quezada Gallo et al., 1999). In a separate study, water vapour permeability of starch films having similar formulations was determined to lie within $0.5-0.6$ g.mm $/ \mathrm{m}^{2} . \mathrm{kPa} . \mathrm{h}$ at $25{ }^{\circ} \mathrm{C}$ for $100 \% / 50 \%$ relative humidity $(\mathrm{RH})$ gradient (Chowdhury \& Das, 2014). Excepting some loss of aroma only for Starch-MC pouch in case of tastemaker powder, these films gave 'Very good' aroma retention of both the test foods. This was 
possible, probably, by storing the pouches over anhydrous calcium chloride in a secondary package so maintaining a dry atmosphere (Fig. 1). It is worth mentioning that at $\approx 11 \% \mathrm{RH}$ within $25-45{ }^{\circ} \mathrm{C}$, films possess $\leq 4 \%$ moisture content (Chowdhury \& Das, 2010; Chowdhury \& Das, 2012). Regarding aroma loss through Starch-MC film, reports of Quezada Gallo et al. (1999) on interaction of aroma compounds with methylcellulose in films deterring the quality of packaged food material and Vidrih et al. (2009) on interaction of aroma with starch in dispersion, seem quite interesting. It may also be noted in the same figure that starch films are transparent and perhaps, such transparency downgrades the colour attributes of tastemaker powder whilst keeping tea unaffected. Thus, as mentioned earlier for protein and fruit based packaging films (McHugh \& Senesi, 2000; Jang et al., 2011; Du et al., 2012) starch based films also have the ability to preserve sensorial attributes of food materials.

\section{Conclusions}

Aroma and taste of tea leaf and tastemaker (culinary powder) in general were assessed as 'Highly important' sensory attributes. These attributes could be maintained 'Very good', at least for 90 days at room temperature, when tea and tastemaker were packed in corn starch-HPMC/AM film, followed by storing the pouches in dry air inside secondary package (plastic jar). Stored alike, market available polypouches exhibited similar sensory quality maintenance. Among all the film-food combinations, starch-HPMC film maintained 'Very good' overall sensory score of tea.

\section{Acknowledgements}

Financial assistance from the Ministry of Environment and Forest, New Delhi, India (Grant No. $19 / 68 / 2005-\mathrm{RE})$ to the first author is acknowledged with thanks.

\section{References}

Arvanitoyannis, I., Nakayama, A., \& Aiba, S. (1998). Edible films made from hydroxypropyl starch and gelatin and plasticized by polyols and water. Carbohydrate Polymers, 36(2-3), 105-119. doi:10.1016/S01448617(98)00017-4

Boonsong, P., Laohakunjit, N., Kerdchoechuen, O., \& Tusvil, P. (2009). Properties and permeability of aroma compounds in food through plasticized cassava films. International Food Research Journal, 16(1), 97-103.

Chakraborty, D., Das, S., \& Das, H. (2013). Aggregation of sensory data using fuzzy logic for sensory quality evaluation of food. Journal of Food Science and Technology-mysore, 50(6), 1088-1096. doi:10.1007/s13197-011-0433-x

Chen, S. (1988). A new approach to handling fuzzy decision-making problems. IEEE Transactions On Systems Man And Cybernetics, 18(6), 1012-1016. doi:10.1109/21.23100

Chinma, C. E., Ariahu, C. C., \& Abu, J. O. (2012). Development and characterization of cassava starch and soy protein concentrate based edible films. International Journal of Food Science and Technology, 47(2), 383-389. doi:10. 1111/j.1365-2621.2011.02851.x

Chowdhury, T. (2013). Development of starch based self-supporting edible films and their characterization (Doctoral dissertation, Indian Institute of Technology Kharagpur, India).

Chowdhury, T. \& Das, M. (2010). Moisture sorption isotherm and isosteric heat of sorption characteristics of starch based edible films containing antimicrobial preservative. International Food Research Journal, 17, 601-614.

Chowdhury, T. \& Das, M. (2012). Moisture sorption isotherm and isosteric heat of sorption of edible films made from blends of starch, amylose and methyl cellulose. International Food Research Journal, 19(4), 1669-1678.

Chowdhury, T. \& Das, M. (2014). Optimization of amount of amylose, methylcellulose and hydroxypropylmethylcellulose for maximum tensile strength and minimum water vapour permeability of corn starch based self-supporting films. Indian Journal of Chemical Technology, 21(2), 96-104.

Das, H. (2005). Sensory evaluation using fuzzy logic. In: Food Processing Operation Analysis (pp. 383-402), 1st edition, New Delhi : Asian Books Pvt. Ltd. 
Das, M. (2008). Effect of screw speed and plasticizer on the torque requirement in single screw extrusion of starch based plastics and their mechanical properties. Indian Journal of Chemical Technology, 15(6), 555.

Das, M. \& Bal, S. (1999). Self-supporting edible films: a field of interest in modern food science. Processed Food Industry, 2(5), 23-25.

Debeaufort, F., Tesson, N., \& Voilley, A. (1995). Aroma compounds and water vapour permeability of edible films and polymeric packagings. Special Publications of the Royal Society of Chemistry, 162, 169-174.

Debeaufort, F. \& Voilley, A. (1994). Aroma compound and water-vapor permeability of edible films and polymeric packagings. Journal of Agricultural and Food Chemistry, 42(12), 2871-2875. doi:10.1021/jf00048a041

Debeaufort, F. \& Voilley, A. (1995). Methyl cellulose-based edible films and coatings .1. effect of plasticizer content water and 1octen-3-ol sorption and transport. Cellulose, 2(3), 205-213. doi:10.1007/BF00813018

Du, W. X., Avena-Bustillos, R. J., Woods, R., Breksa, A. P., McHugh, T. H., Friedman, M., ... Mandrell, R. (2012). Sensory evaluation of baked chicken wrapped with antimicrobial apple and tomato edible films formulated with cinnamaldehyde and carvacrol. Journal of Agricultural and Food Chemistry, 60(32), 7799-7804. doi:10.1021/jf301281a

Fabra, M. J., Hambleton, A., Talens, P., Debeaufort, F., \& Chiralt, A. (2011). Effect of ferulic acid and alpha-tocopherol antioxidants on properties of sodium caseinate edible films. Food Hydrocolloids, 25(6), 14411447. doi:10.1016/j.foodhyd.2011.01.012

Fabra, M. J., Hambleton, A., Talens, P., Debeaufort, F., Chiralt, A., \& Voilley, A. (2008, May). Aroma barrier properties of sodium caseinate-based films. Biomacromolecules, 9(5), 1406-1410. doi:10.1021/bm701363p

Habeych, E., van der Goot, A. J., \& Boom, R. (2007). Prediction of permeation fluxes of small volatile components through starchbased films. Carbohydrate Polymers, 68(3), 528-536. doi:10.1016/j.carbpol.2006.11.010

Hambleton, A., Debeaufort, F., Bonnotte, A., \& Voilley, A. (2009). Influence of alginate emulsion-based films structure on its barrier properties and on the protection of microencapsulated aroma compound. Food Hydrocolloids, 23(8), 2116-2124. doi:10.1016/j . foodhyd.2009.04.001

Jang, S. A., Shin, Y. J., \& Song, K. B. (2011). Effect of rapeseed protein-gelatin film containing grapefruit seed extract on 'maehyang' strawberry quality. International Journal of Food Science and Technology, 46(3), 620625. doi:10.1111/j.1365-2621.2010.02530.x

Jaya, S. \& Das, H. (2003). Sensory evaluation of mango drinks using fuzzy logic. Journal of Sensory Studies, 18(2), 163-176. doi:10. 1111/j.1745-459X.2003.tb00382.x

Jouquand, C., Malhiac, C., \& Grisel, M. (2006). Determination of specific interactions between aroma compounds and xanthan/galactomannan mixtures. Developments in Food Science, 43, 421-424.

Langourieux, S. \& Crouzet, J. (1995). Interactions between polysaccharides and aroma compounds. Developments in Food Science, 37, 1173-1186.

Lee, J. \& Chambers, D. H. (2007). A lexicon for flavor descriptive analysis of green tea. Journal of Sensory Studies, 22(3), 256-272. doi:10. 1111/j.1745-459X.2007.00105.X

Liang, Y. R., Ye, Q., Jin, J., Liang, H., Lu, J. L., Du, Y. Y., \& Dong, J. J. (2008). Chemical and instrumental assessment of green tea sensory preference. International Journal of Food Properties, 11(2), 258-272. doi:10. 1080/10942910701299430

Longares, A., Monahan, F. J., O'Riordan, E. D., \& O'Sullivan, M. (2004). Physical properties and sensory evaluation of wpi films of varying thickness. Lebensmittel-Wissenschaft Und-technologie-Food Science and Technology, 37(5), 545-550. doi:10.1016/j.lwt.2003. 12.005

Maizura, M., Fazilah, A., Norziah, M. H., \& Karim, A. A. (2007). Antibacterial activity and mechanical properties of partially hydrolyzed sago starch-alginate edible film containing lemongrass oil. Journal of Food Science, 72(6), C324-C330. doi:10.1111/j.17503841.2007.00427.x

Mali, S., Grossmann, M. V. E., Garcia, M. A., Martino, M. N., \& Zaritzky, N. E. (2004). Barrier, mechanical and optical properties of plasti- 
cized yam starch films. Carbohydrate Polymers, 56 (2), 129-135. doi:10.1016/j.carbpol. 2004.01.004

McHugh, T. H. \& Senesi, E. (2000). Apple wraps: a novel method to improve the quality and extend the shelf life of fresh-cut apples. Journal of Food Science, 65(3), 480-485. doi:10. 1111/j.1365-2621.2000.tb16032.x

Paes, S. S., Yakimets, I., \& Mitchell, J. R. (2008). Influence of gelatinization process on functional properties of cassava starch films. Food Hydrocolloids, 22(5), 788-797. doi:10.1016/ j.foodhyd.2007.03.008

Quezada Gallo, J. A., Debeaufort, F., \& Voilley, A. (1999). Interactions between aroma and edible films. 1. permeability of methylcellulose and low-density polyethylene films to methyl ketones. Journal of Agricultural and Food Chemistry, 47(1), 108-113.

Ranganna, S. (1986). Handbook of analysis and quality control for fruit and vegetable products. Tata McGraw-Hill Education.

Rindlav-Westling, A., Stading, M., \& Gatenholm, P. (2002). Crystallinity and morphology in films of starch, amylose and amylopectin blends. Biomacromolecules, 3(1), 84-91. doi:10.1021/bm010114i

Routray, W. \& Mishra, H. N. (2012). Sensory evaluation of different drinks formulated from dahi (indian yogurt) powder using fuzzy logic. Journal of Food Processing and Preservation, 36(1), 1-10. doi:10.1111/j.1745-4549. 2011.00545.x

Sebti, I., Chollet, E., Degraeve, P., Noel, C., \& Peyrol, E. (2007). Water sensitivity, antimicrobial, and physicochemical analyses of edible films based on hpmc and/or chitosan. Journal of Agricultural and Food Chemistry, 55(3), 693-699. doi:10.1021/jf062013n

Sereno, N. M., Hill, S. E., Taylor, A. J., Mitchell, J. R., \& Davies, S. J. (2009). Aroma permeability of hydroxypropyl maize starch films. Journal of Agricultural and Food Chemistry, 57(3), 985-990. doi:10.1021/jf8036775

Singh, K. P., Mishra, A., \& Mishra, H. N. (2012). Fuzzy analysis of sensory attributes of bread prepared from millet-based composite flours. LWT-Food Science and Technology, 48(2), 276-282. doi:10.1016/j.lwt.2012.03.026

Sinija, V. R. \& Mishra, H. N. (2011). Fuzzy analysis of sensory data for quality evaluation and ranking of instant green tea powder and granules. Food and Bioprocess Technology, 4(3), 408-416. doi:10 . 1007 / s11947 - 008 0163-X

Tao, J., Cui, Y., Ji, X., Ma, L., \& Wo, D. (2007). Properties of biodegradable thermoplastic starch/ethyl cellulose composite. In J. Kim, D. Wo, L. Zhou, H. Huang, K. Lau, \& M. Wang (Eds.), Advances in composite materials and structures, pts 1 and 2 (Vol. 334335, 1-2, pp. 345-348). Key Engineering Materials. 5th Asian/Australasian Conference on Composite Materials (ACCM-5), Hong Kong, PEOPLES R CHINA, NOV 27-30, 2006.

Terta, M., Blekas, G., \& Paraskevopoulou, A. (2006). Retention of selected aroma compounds by polysaccharide solutions: a thermodynamic and kinetic approach. Food Hydrocolloids, 20(6), 863-871. doi:10.1016/j . foodhyd.2005.08.011

UPASI. (2014). Tea research foundation. Retrieved from http://www.upasitearesearch.org/teatasting

Uprit, S. \& Mishra, H. N. (2002). Fuzzy multiattribute decision making approach for development and comparison of soy fortified paneer. Journal of Sensory Studies, 17(2), 163176. doi:10.1111/j.1745-459X.2002.tb00340. $\mathrm{x}$

van Willige, R. W. G. (2002). Effects of flavour absorption on foods and their packaging materials. Wageningen Universiteit.

Vidrih, R., Zlatić, E., \& Hribar, J. (2009). Release of strawberry aroma compounds by different starch-aroma systems. Czech Journal of Food Science, 27, S58-S61. Retrieved from http : / / www . agriculturejournals . cz / web / cjfs.htm volume $=27 \&$ firstPage $=$ S58\&type $=$ publishedArticle

Voilley, A., Debeaufort, F., \& Quezada-Gallo, J. A. (2002). Protein-based films and coatings. In G. Aristippos (Ed.), (Chap. Edible films and coatings as aroma barriers). CRC Press.

Yilmaz, G., Jongboom, R. O. J., Feil, H., van Dijk, C., \& Hennink, W. E. (2004). Permeation of volatile compounds through starch films. Biomacromolecules, 5(2), 650-656. doi:10 . 1021/bm034493m 
Table 1: The triplets associated with five-point sensory scale

\begin{tabular}{ccccc}
\hline $\begin{array}{c}\text { Not satisfactory/ } \\
\text { Not at all important }\end{array}$ & $\begin{array}{c}\text { Fair/ } \\
\text { Somewhat important }\end{array}$ & $\begin{array}{c}\text { Medium/ } \\
\text { Important }\end{array}$ & $\begin{array}{c}\text { Good/ } \\
\text { Highly important }\end{array}$ & $\begin{array}{c}\text { Excellent/ } \\
\text { Extremely important }\end{array}$ \\
\hline 0025 & 252525 & 502525 & 752525 & 100250 \\
\hline
\end{tabular}

Table 2: Evaluation of quality attributes of tea samples and triplets corresponding to the scores

\begin{tabular}{|c|c|c|c|c|c|c|}
\hline \multirow{2}{*}{$\begin{array}{l}\text { Sensory quality } \\
\text { attributes of tea samples }\end{array}$} & \multicolumn{5}{|c|}{ Number of judges for different scale factors } & \multirow{2}{*}{$\begin{array}{l}\text { Triplets for sensory } \\
\text { scores }\end{array}$} \\
\hline & $\begin{array}{c}\text { Not } \\
\text { Satisfactory }\end{array}$ & Fair & Medium & Good & Excellent & \\
\hline \multicolumn{7}{|l|}{ Aroma } \\
\hline Sample 467 & 0 & 0 & 1 & 15 & 9 & $\mathrm{~S} 467 \mathrm{~A}=(832516)$ \\
\hline Sample 785 & 0 & 0 & 0 & 17 & 8 & $\mathrm{~S} 785 \mathrm{~A}=(832517)$ \\
\hline Sample 598 & 0 & 2 & 3 & 14 & 6 & $\mathrm{~S} 598 \mathrm{~A}=\left(\begin{array}{lll}74 & 25 & 19\end{array}\right)$ \\
\hline Sample 770 & 0 & 2 & 2 & 14 & 7 & $\mathrm{~S} 770 \mathrm{~A}=\left(\begin{array}{lll}76 & 25 & 18\end{array}\right)$ \\
\hline \multicolumn{7}{|l|}{ Colour } \\
\hline Sample 467 & 0 & 4 & 6 & 11 & 4 & $\mathrm{~S} 467 \mathrm{C}=\left(\begin{array}{lll}65 & 25 & 21\end{array}\right)$ \\
\hline Sample 785 & 2 & 3 & 5 & 14 & 1 & $\mathrm{~S} 785 \mathrm{C}=\left(\begin{array}{lll}59 & 23 & 24\end{array}\right)$ \\
\hline Sample 598 & 2 & 4 & 9 & 10 & 0 & $\mathrm{~S} 598 \mathrm{C}=\left(\begin{array}{lll}52 & 23 & 25\end{array}\right)$ \\
\hline Sample 770 & 3 & 2 & 4 & 12 & 4 & $\mathrm{~S} 770 \mathrm{C}=\left(\begin{array}{lll}62 & 22 & 21\end{array}\right)$ \\
\hline \multicolumn{7}{|l|}{ Taste } \\
\hline Sample 467 & 0 & 2 & 4 & 15 & 4 & $\mathrm{~S} 467 \mathrm{~T}=\left(\begin{array}{lll}71 & 25 & 21\end{array}\right)$ \\
\hline Sample 785 & 0 & 4 & 5 & 11 & 5 & $\mathrm{~S} 785 \mathrm{~T}=\left(\begin{array}{lll}67 & 25 & 20\end{array}\right)$ \\
\hline Sample 598 & 0 & 6 & 11 & 6 & 2 & $\mathrm{~S} 598 \mathrm{~T}=\left(\begin{array}{lll}54 & 25 & 23\end{array}\right)$ \\
\hline Sample 770 & 0 & 1 & 11 & 10 & 3 & $\mathrm{~S} 770 \mathrm{~T}=\left(\begin{array}{lll}65 & 25 & 22\end{array}\right)$ \\
\hline \multicolumn{7}{|l|}{ Strength } \\
\hline Sample 467 & 0 & 1 & 2 & 13 & 9 & $\mathrm{~S} 467 \mathrm{~S}=\left(\begin{array}{lll}80 & 25 & 16\end{array}\right)$ \\
\hline Sample 785 & 2 & 4 & 8 & 8 & 3 & $\mathrm{~S} 785 \mathrm{~S}=\left(\begin{array}{lll}56 & 23 & 22\end{array}\right)$ \\
\hline Sample 598 & 1 & 2 & 17 & 5 & 0 & $\mathrm{~S} 598 \mathrm{~S}=\left(\begin{array}{lll}51 & 24 & 25\end{array}\right)$ \\
\hline Sample 770 & 0 & 7 & 9 & 7 & 2 & $\mathrm{~S} 770 \mathrm{~S}=\left(\begin{array}{lll}54 & 25 & 23\end{array}\right)$ \\
\hline
\end{tabular}


$44 \mid$ Chowdhury and Das

Table 3: Evaluation of quality attributes of tastemaker samples and triplets corresponding to the scores

\begin{tabular}{|c|c|c|c|c|c|c|}
\hline \multirow{2}{*}{$\begin{array}{l}\text { Sensory quality } \\
\text { attributes of } \\
\text { tastemaker samples }\end{array}$} & \multicolumn{5}{|c|}{ Number of judges for different scale factors } & \multirow{2}{*}{$\begin{array}{l}\text { Triplets for sensory } \\
\text { scores }\end{array}$} \\
\hline & $\begin{array}{c}\text { Not } \\
\text { Satisfactory }\end{array}$ & Fair & Medium & Good & Excellent & \\
\hline \multicolumn{7}{|l|}{ Aroma } \\
\hline Sample 467 & 0 & 1 & 5 & 11 & 8 & $\mathrm{~S} 467 \mathrm{~A}=\left(\begin{array}{lll}76 & 25 & 17\end{array}\right)$ \\
\hline Sample 785 & 0 & 2 & 6 & 7 & 10 & $\mathrm{~S} 785 \mathrm{~A}=\left(\begin{array}{lll}75 & 25 & 15\end{array}\right)$ \\
\hline Sample 598 & 2 & 8 & 7 & 5 & 3 & $\mathrm{~S} 598 \mathrm{~A}=\left(\begin{array}{l}492322\end{array}\right)$ \\
\hline Sample 770 & 0 & 1 & 6 & 8 & 10 & $\mathrm{~S} 770 \mathrm{~A}=\left(\begin{array}{lll}77 & 25 & 15\end{array}\right)$ \\
\hline \multicolumn{7}{|l|}{ Colour } \\
\hline Sample 467 & 0 & 2 & 5 & 10 & 8 & $\mathrm{~S} 467 \mathrm{C}=\left(\begin{array}{lll}66 & 25 & 20\end{array}\right)$ \\
\hline Sample 785 & 0 & 4 & 12 & 4 & 5 & $\mathrm{~S} 785 \mathrm{C}=\left(\begin{array}{lll}60 & 25 & 20\end{array}\right)$ \\
\hline Sample 598 & 1 & 3 & 7 & 11 & 3 & $\mathrm{~S} 598 \mathrm{C}=\left(\begin{array}{lll}62 & 24 & 22\end{array}\right)$ \\
\hline Sample 770 & 0 & 0 & 3 & 5 & 17 & $\mathrm{~S} 770 \mathrm{C}=\left(\begin{array}{lll}89 & 25 & 8\end{array}\right)$ \\
\hline \multicolumn{7}{|l|}{ Taste } \\
\hline Sample 467 & 0 & 2 & 2 & 7 & 14 & $\mathrm{~S} 467 \mathrm{~T}=\left(\begin{array}{lll}83 & 25 & 11\end{array}\right)$ \\
\hline Sample 785 & 0 & 2 & 5 & 9 & 9 & $\mathrm{~S} 785 \mathrm{~T}=\left(\begin{array}{lll}75 & 25 & 16\end{array}\right)$ \\
\hline Sample 598 & 1 & 0 & 2 & 7 & 15 & $\mathrm{~S} 598 \mathrm{~T}=(852410)$ \\
\hline Sample 770 & 0 & 0 & 5 & 9 & 11 & $\mathrm{~S} 770 \mathrm{~T}=\left(\begin{array}{lll}81 & 25 & 14\end{array}\right)$ \\
\hline \multicolumn{7}{|l|}{ Appearance } \\
\hline Sample 467 & 0 & 4 & 13 & 6 & 2 & $\mathrm{~S} 467 \mathrm{Ap}=\left(\begin{array}{lll}46 & 25 & 23\end{array}\right)$ \\
\hline Sample 785 & 0 & 6 & 14 & 3 & 2 & $\mathrm{~S} 785 \mathrm{Ap}=\left(\begin{array}{lll}51 & 2523\end{array}\right)$ \\
\hline Sample 598 & 1 & 2 & 17 & 5 & 0 & $\mathrm{~S} 598 \mathrm{Ap}=\left(\begin{array}{lll}51 & 2425\end{array}\right)$ \\
\hline Sample 770 & 0 & 0 & 4 & 10 & 11 & $\mathrm{~S} 770 \mathrm{Ap}=\left(\begin{array}{lll}82 & 25 & 14\end{array}\right)$ \\
\hline
\end{tabular}

Table 4: Evaluation of quality attributes of tea and tastemaker in general and triplets corresponding to the scores

\begin{tabular}{|c|c|c|c|c|c|c|c|c|}
\hline \multirow[t]{2}{*}{$\begin{array}{l}\text { Quality attributes } \\
\text { in general }\end{array}$} & \multicolumn{5}{|c|}{$\begin{array}{l}\text { Number of judges for } \\
\text { different scale factors }\end{array}$} & \multirow{2}{*}{\multicolumn{2}{|c|}{$\begin{array}{l}\text { Triplets for sensory } \\
\text { scores }\end{array}$}} & \multirow[t]{2}{*}{$\begin{array}{l}\text { Triplets for relative } \\
\text { weighting }\end{array}$} \\
\hline & NI & SI & $\mathrm{I}$ & $\mathrm{HI}$ & EI & & & \\
\hline \multicolumn{9}{|l|}{ Tea } \\
\hline Aroma & 0 & 1 & 3 & 15 & 6 & $\mathrm{QA}=$ & $\left(\begin{array}{lll}76 & 25 & 19\end{array}\right)$ & QArel $=\left(\begin{array}{lll}0.248 & 0.081 & 0.062\end{array}\right)$ \\
\hline Colour & 0 & 2 & 6 & 6 & 11 & $\mathrm{QC}=$ & $\left(\begin{array}{lll}76 & 25 & 14\end{array}\right)$ & QCrel $=\left(\begin{array}{lll}0.248 & 0.081 & 0.046\end{array}\right)$ \\
\hline Taste & 0 & 0 & 4 & 5 & 16 & $\mathrm{QT}=$ & $(87259)$ & QTrel $=\left(\begin{array}{lll}0.283 & 0.081 & 0.029\end{array}\right)$ \\
\hline Strength & 1 & 4 & 5 & 6 & 9 & $\mathrm{QS}=$ & $\left(\begin{array}{llll}68 & 24 & 16\end{array}\right)$ & QSrel $=\left(\begin{array}{lll}0.222 & 0.078 & 0.052\end{array}\right)$ \\
\hline \multicolumn{9}{|l|}{ Tastemaker } \\
\hline Aroma & 0 & 1 & 6 & 8 & 10 & $\mathrm{QA}=$ & $\left(\begin{array}{lll}77 & 25 & 15\end{array}\right)$ & QArel $=\left(\begin{array}{lll}0.285 & 0.093 & 0.057\end{array}\right)$ \\
\hline Colour & 1 & 2 & 8 & 12 & 2 & $\mathrm{QC}=$ & $\left(\begin{array}{lll}62 & 24 & 23\end{array}\right)$ & QCrel $=\left(\begin{array}{lll}0.229 & 0.089 & 0.085\end{array}\right)$ \\
\hline Taste & 0 & 2 & 3 & 9 & 11 & $\mathrm{QT}=$ & $\left(\begin{array}{lll}79 & 24 & 14\end{array}\right)$ & QTrel $=\left(\begin{array}{lll}0.293 & 0.093 & 0.052\end{array}\right)$ \\
\hline Appearance & 2 & 4 & 11 & 6 & 2 & $\mathrm{QAp}=$ & $\left(\begin{array}{lll}52 & 23 & 23\end{array}\right)$ & QAprel $=\left(\begin{array}{lll}0.193 & 0.085 & 0.085\end{array}\right)$ \\
\hline
\end{tabular}

$N I$ not at all important, $S I$ somewhat important, $I$ important, $H I$ highly important, $E I$ extremely important. 
Sensory Quality Retention of Packed Foods $\mid 45$

Table 5: Membership function values of different tea and tastemaker samples based on overall sensory score

\begin{tabular}{|c|c|c|c|c|c|c|c|c|c|c|}
\hline \multicolumn{6}{|c|}{ Membership function } & \multicolumn{5}{|l|}{ Values } \\
\hline \multicolumn{11}{|l|}{ Tea } \\
\hline B467 & 0 & 0 & 0.0939 & 0.2976 & 0.5013 & 0.7050 & 0.9088 & 1.0000 & 0.8327 & 0.5298 \\
\hline B785 & 0 & 0 & 0.1961 & 0.4161 & 0.6361 & 0.8560 & 1.0000 & 0.8965 & 0.5971 & 0.2977 \\
\hline B598 & 0 & 0.1197 & 0.3526 & 0.5856 & 0.8185 & 1.0000 & 0.9353 & 0.6424 & 0.3495 & 0.0566 \\
\hline B770 & 0 & 0.0103 & 0.2325 & 0.4547 & 0.6769 & 0.8990 & 1.0000 & 0.8358 & 0.5349 & 0.2340 \\
\hline \multicolumn{11}{|c|}{ Tastemaker } \\
\hline B467 & 0 & 0 & 0.1926 & 0.3946 & 0.5965 & 0.7985 & 1.0000 & 0.9993 & 0.7148 & 0.4304 \\
\hline B785 & 0 & 0.0336 & 0.2395 & 0.4454 & 0.6513 & 0.8572 & 1.0000 & 0.9136 & 0.6318 & 0.3501 \\
\hline B598 & 0 & 0.0669 & 0.2844 & 0.5019 & 0.7193 & 0.9368 & 1.0000 & 0.8019 & 0.5227 & 0.2436 \\
\hline B770 & 0 & 0 & 0.0484 & 0.2318 & 0.4152 & 0.5986 & 0.7820 & 0.9654 & 1.0000 & 0.7744 \\
\hline
\end{tabular}

Table 6: Similarity values (based on overall sensory score) of tea and tastemaker samples and their ranking

\begin{tabular}{lcccc}
\hline \multicolumn{5}{c}{ Similarity values of tea } \\
\hline Sensory scales & Sample 467 & Sample 785 & Sample 598 & Sample 770 \\
\hline Not satisfactory, F1 & 0 & 0 & 0.0168 & 0.0015 \\
Fair, F2 & 0.0666 & 0.1123 & 0.2146 & 0.1318 \\
Satisfactory, F3 & 0.3287 & 0.4386 & 0.5837 & 0.4759 \\
Good, F4 & 0.6486 & 0.7288 & 0.7479 & 0.7445 \\
Very good, F5 & 0.7000 & 0.5955 & 0.4174 & 0.5573 \\
Excellent, F6 & 0.2595 & 0.1657 & 0.0649 & 0.1406 \\
Ranking & I & IV & II & III \\
\hline & Similarity values of tastemaker & \\
\hline Sensory scales & Sample 467 & Sample 785 & Sample 598 & Sample 770 \\
\hline Not satisfactory, F1 & 0 & 0.0045 & 0.0090 & 0 \\
Fair, F2 & 0.1004 & 0.1314 & 0.1624 & 0.0440 \\
Satisfactory, F3 & 0.3831 & 0.4361 & 0.4940 & 0.2605 \\
Good, F4 & 0.6690 & 0.6997 & 0.7275 & 0.5552 \\
Very good, F5 & 0.6259 & 0.5886 & 0.5429 & 0.7356 \\
Excellent, F6 & 0.2030 & 0.1765 & 0.1362 & 0.3417 \\
Ranking & IV & III & II & I \\
\hline
\end{tabular}


$46 \mid$ Chowdhury and Das

Table 7: Similarity values of quality attributes of tea and tastemaker in general and their ranking

\begin{tabular}{|c|c|c|c|c|}
\hline \multicolumn{5}{|c|}{ Similarity values of tea } \\
\hline Sensory scales & Aroma & Colour & Taste & Strength \\
\hline Not at all necessary, F1 & 0 & 0 & 0 & 0 \\
\hline Somewhat necessary, F2 & 0 & 0 & 0 & 0 \\
\hline Necessary, F3 & 0.0720 & 0.0720 & 0 & 0.2333 \\
\hline Important, F4 & 0.6480 & 0.6480 & 0.2780 & 0.8917 \\
\hline Highly important, F5 & 0.9204 & 0.8377 & 0.8853 & 0.6500 \\
\hline Extremely important, F6 & 0.2742 & 0.1611 & 0.5649 & 0.0535 \\
\hline Ranking & I & III & II & IV \\
\hline \multicolumn{5}{|c|}{ Similarity values of tastemaker } \\
\hline Sensory scales & Aroma & Colour & Taste & Appearance \\
\hline Not at all necessary, F1 & 0 & 0 & 0 & 0 \\
\hline Somewhat necessary, F2 & 0 & 0.0162 & 0 & 0.1114 \\
\hline Necessary, F3 & 0.0640 & 0.4053 & 0.0480 & 0.7541 \\
\hline Important, F4 & 0.6160 & 0.9700 & 0.5520 & 0.8741 \\
\hline Highly important, F5 & 0.8907 & 0.5329 & 0.9423 & 0.2142 \\
\hline Extremely important, F6 & 0.2341 & 0.0423 & 0.2857 & 0 \\
\hline Ranking & II & III & I & IV \\
\hline
\end{tabular}


Table 8: Similarity values for individual quality attribute of different tea samples

\begin{tabular}{lcccc}
\hline Scale factors & Aroma & Colour & Taste & Strength \\
\hline Sample 467 & & & & \\
Not satisfactory, F1 & 0 & 0.0048 & 0 & 0 \\
Fair, F2 & 0.0245 & 0.1455 & 0.0341 & 0.0840 \\
Satisfactory, F3 & 0.5532 & 0.4849 & 0.2528 & 0.3716 \\
Good, F4 & 0.5519 & 0.7439 & 0.5692 & 0.6942 \\
Very good, F5 & 0.7532 & 0.5466 & 0.7437 & 0.6547 \\
Excellent, F6 & 0.3548 & 0.1329 & 0.3266 & 0.2010 \\
Sample 785 & & & & \\
Not satisfactory, F1 & 0 & 0.0119 & 0 & 0 \\
Fair, F2 & 0.0255 & 0.1931 & 0.0626 & 0.2569 \\
Satisfactory, F3 & 0.2339 & 0.5670 & 0.3187 & 0.7451 \\
Good, F4 & 0.5519 & 0.7533 & 0.6392 & 0.6990 \\
Very good, F5 & 0.7532 & 0.4373 & 0.7149 & 0.2115 \\
Excellent, F6 & 0.3555 & 0.0766 & 0.2699 & 0.0038 \\
Sample 598 & & & & \\
Not satisfactory, F1 & 0 & 0.0297 & 0.0141 & 0.0657 \\
Fair, F2 & 0.0728 & 0.2927 & 0.1900 & 0.4177 \\
Satisfactory, F3 & 0.3359 & 0.6887 & 0.5329 & 0.7862 \\
Good, F4 & 0.6440 & 0.7059 & 0.7457 & 0.6156 \\
Very good, F5 & 0.6805 & 0.2874 & 0.4681 & 0.1574 \\
Excellent, F6 & 0.2549 & 0.0240 & 0.0883 & 0 \\
Sample 770 & & & & \\
Not satisfactory, F1 & 0 & 0.0020 & 0 & 0.0519 \\
Fair, F2 & 0.0617 & 0.1463 & 0.0757 & 0.3711 \\
Satisfactory, F3 & 0.3134 & 0.5233 & 0.3442 & 0.7563 \\
Good, F4 & 0.6260 & 0.7719 & 0.6572 & 0.6552 \\
Very good, F5 & 0.7028 & 0.4885 & 0.6867 & 0.1811 \\
Excellent, F6 & 0.2775 & 0.0914 & 0.2459 & 0 \\
\hline & & & &
\end{tabular}


$48 \mid$ Chowdhury and Das

Table 9: Similarity values for individual quality attribute of different tastemaker samples

\begin{tabular}{lcccc}
\hline Scale factors & Aroma & Colour & Taste & Appearance \\
\hline Sample 467 & & & & \\
Not satisfactory, F1 & 0 & 0.0158 & 0 & 0.1705 \\
Fair, F2 & 0.0249 & 0.1879 & 0.0086 & 0.6308 \\
Satisfactory, F3 & 0.2242 & 0.5030 & 0.1628 & 0.7945 \\
Good, F4 & 0.5235 & 0.6967 & 0.5011 & 0.3899 \\
Very good, F5 & 0.7604 & 0.4894 & 0.8523 & 0.0409 \\
Excellent, F6 & 0.3984 & 0.1374 & 0.5182 & 0 \\
Sample 785 & & & & \\
Not satisfactory, F1 & 0 & 0.0278 & 0 & 0.1268 \\
Fair, F2 & 0.0268 & 0.2600 & 0.0232 & 0.5279 \\
Satisfactory, F3 & 0.2337 & 0.6059 & 0.2163 & 0.7832 \\
Good, F4 & 0.5349 & 0.7036 & 0.5152 & 0.4806 \\
Very good, F5 & 0.7576 & 0.3922 & 0.7649 & 0.0957 \\
Excellent, F6 & 0.3843 & 0.0752 & 0.4103 & 0 \\
Sample 598 & & & & \\
Not satisfactory, F1 & 0.0263 & 0.0212 & 0 & 0.1193 \\
Fair, F2 & 0.2551 & 0.2243 & 0.0003 & 0.5167 \\
Satisfactory, F3 & 0.6091 & 0.5623 & 0.1327 & 0.7787 \\
Good, F4 & 0.7207 & 0.7026 & 0.4940 & 0.4933 \\
Very good, F5 & 0.3866 & 0.4415 & 0.8862 & 0.1091 \\
Excellent, F6 & 0.0597 & 0.1101 & 0.5554 & 0 \\
Sample 770 & & & & \\
Not satisfactory, F1 & 0 & 0 & 0 & 0.0111 \\
Fair, F2 & 0.0231 & 0.0453 & 0.0126 & 0.1660 \\
Satisfactory, F3 & 0.2157 & 0.2611 & 0.1763 & 0.4808 \\
Good, F4 & 0.5146 & 0.5534 & 0.5003 & 0.7050 \\
Very good, F5 & 0.7652 & 0.7319 & 0.8252 & 0.5823 \\
Excellent, F6 & 0.4111 & 0.3408 & 0.4896 & 0.1537 \\
\hline & & & &
\end{tabular}

